\begin{tabular}{|c|c|}
\hline Title & A $n$ infantileðuvenile form of A lexander disease caused by a R79H mutation in GFAP \\
\hline Author(s) & A sahina, Naoko; Okamoto, Takay uki; Sudo, A kira; Kanazawa, Naomi; Tsujino, Seiichi; Saitoh, Shinji \\
\hline Citation & $\begin{array}{l}\text { Brain and Development, 28(2), 131-133 } \\
\text { https://doi.org/10.1016/.braindev.2005.05.004 }\end{array}$ \\
\hline Issue Date & 2006-03 \\
\hline Doc URL & http:/hdl.handle.net/2115/8415 \\
\hline Type & article (author version) \\
\hline File Information & asahina.pdf \\
\hline
\end{tabular}

Instructions for use 
N. Asahina, et al. 1

\section{An infantile/juvenile form of Alexander disease caused by a R79H mutation in}

\section{GFAP}

Naoko ASAHINA ${ }^{\mathrm{a}}$, Takayuki OKAMOTO ${ }^{\mathrm{a}}$, Akira SUDO ${ }^{\mathrm{a}}$, Naomi KANAZAWA ${ }^{\mathrm{b}}$,

Seiichi TSUJINO ${ }^{\mathrm{b}}$, Shinji SAITOH ${ }^{\mathrm{a}}$

${ }^{a}$ Department of Pediatrics, Hokkaido University Graduate School of Medicine, Sapporo, Japan

${ }^{\mathrm{b}}$ Department of Inherited Metabolic Disease, National Institute of Neuroscience,

National Center of Neurology and Psychiatry, Tokyo, Japan

Corresponding author: Shinji Saitoh,

Department of Pediatrics, Hokkaido University Graduate School of Medicine, Kita 15,

Nishi 7, Kita-ku, Sapporo 060-8638, Japan.

Tel.: +81-11-706-5954; fax: +81-11-706-7898; E-mail: ss11@med.hokudai.ac.jp 
N. Asahina, et al. 2

\section{Abstract}

Alexander disease is a degenerative white matter disorder due to mutations in the glial fibrillary acidic protein (GFAP) gene. It has been classified into three forms based on the age of onset and severity: an infantile, a juvenile, and an adult form. In a six-yearold patient with a relatively mild form of Alexander disease, we detected a common R79H mutation in GFAP previously only described in the infantile form. These results suggest the need for further studies of the genotype-phenotype correlation.

Key Words: Alexander disease; glial fibrillary acidic protein; genotype-phenotype correlation; infantile form; juvenile form. 
N. Asahina, et al. 3

\section{Introduction}

Alexander disease (AD) is a form of leukodystrophy that predominantly affects the frontal lobe of the brain. While diagnosis was previously based on neuropathological findings characterized by the presence of Rosenthal fibers in astrocytes [1], AD can now also be diagnosed without histological confirmation, by characteristic magnetic resonance imaging (MRI) findings [2]. Recently, mutations in the glial fibrillary acidic protein (GFAP) gene were identified in AD patients [3-5]. This has facilitated the genetic diagnosis of mild $\mathrm{AD}$ patients, and the discovery of different clinical manifestations of AD [4-9]. However, genotype-phenotype correlations have yet to be determined. Here we describe a six-year-old boy with AD resembling the juvenile form of the disease, albeit with the GFAP R79H missense mutation. This mutation has only been associated previously with the infantile form of AD.

\section{Case report}

The patient (a 6-year-old boy) was the second child of non-consanguineous, healthy Japanese parents. His elder brother was healthy. The patient was born at 40 weeks 
gestation without prenatal or perinatal difficulties. Birth weight was 2550 g (-1.6 SD), length was $46 \mathrm{~cm}(-2.0 \mathrm{SD})$ and head circumference was $31 \mathrm{~cm}(-1.8 \mathrm{SD})$.

Developmental milestones were slightly delayed; for example, the patient gained head control at five months, stood with help at 12 months, walked alone at 20 months, and first spoke at 24 months. At five years of age, he experienced his first seizure. He suddenly became unresponsive, and his eyes deviated to the left for a few minutes while eating. Similar episodes occurred several times over a period of one month. Valproic acid and clobazam were administered and the seizures stopped. There was no deterioration in physical and mental status. The patient was referred to our hospital because white matter lesions of unknown origin were repeatedly detected on serial MRI scans over an 18-month period. On physical examination, his height was $117.4 \mathrm{~cm} \mathrm{(-0.2}$ SD), weight was $20.6 \mathrm{~kg}(-5 \%)$ and head circumference was $53.5 \mathrm{~cm}$ (+1.1 SD). Skin lesions and hepatosplenomegaly were not observed. Cranial nerve and deep tendon reflexes were normal, and pathological reflexes were absent. He could run, jump and stand on one leg. He had dysarthria (slurred speech) but did not have an ataxic gait or intention tremor. Involuntary movement and sensory abnormalities were not observed. 
Intelligence quotient (Tanaka-Binet) was 56 at five years and 11 months. Metabolic screening did not reveal any abnormality.

T2-weighted MRI (Fig. 1A) revealed a high-intensity signal in the bilateral frontal white matter and basal ganglia (Fig. 1A). T1-weighted imaging showed a low-intensity signal in the same area (Fig. 1B). The subcortical U-fibers were spared. MRI also revealed enhancement in parts of the white matter adjacent to the frontal horns (Fig. 1C). A periventricular rim was detected with a high-intensity signal on T1-weighted images (Fig. 1B) and a low-intensity signal on T2-weighted images (Fig. 1A). Magnetic resonance spectroscopy of frontal white matter showed a high choline/creatine ratio (1.80) and a low N-acetyl-aspartate/creatine ratio (0.50).

${ }^{18}$ F-FDG Positron Emission Tomography showed mild, but ambiguous, hypometabolic areas in the bilateral frontal lobe (Fig. 1D). Electroencephalograms displayed sporadic, diffuse spike-waves during sleep, but definite focal epileptic discharges were not present. Brainstem auditory evoked potentials showed prolonged latencies between waves III and V (2.56 ms and $2.28 \mathrm{~ms}$ on left and right stimulation of $90 \mathrm{~dB}$ ). Somatosensory evoked potentials showed a normal central conduction time (5.6 ms on 
N. Asahina, et al. 6

right medial nerve stimulation) between the cervical cord and cortex. Motor and sensory nerve conduction velocities were normal.

Genomic DNA was isolated from the patient's peripheral leukocytes after informed consent was obtained following a full explanation of the procedure undertaken. Exons of the GFAP gene were PCR amplified and sequenced as previously described [5]. A heterozygous G-to-A transition at nucleotide 250 (250G>A) in exon 1 was identified (data not shown). This resulted in the substitution of an arginine with a histidine at codon $79(\mathrm{R} 79 H)$. Genetic analysis of the patient's parents could not be performed.

\section{Discussion}

Alexander disease is clinically divided into three forms: an infantile, a juvenile and an adult form [10]. The infantile form is characterized by progressive megalencephaly, with or without hydrocephalus, psychomotor deterioration, spasticity and seizures. The average age of onset is six months (range 0-24 months), and the average age of survival after diagnosis is 2.4 years (range 0.2-7.6 years) [10]. The juvenile form shows progressive spasticity with hyperreflexia, bulbar symptoms and ataxia. Macrocephaly 
and seizures may be observed. Mental and sensory functions are usually normal. The mean age of onset of the juvenile form is 9.6 years (range 7-14 years) [10]. Nevertheless, the distinction between the infantile and juvenile forms is not clear. Mutations in the GFAP gene have recently been identified in AD patients [3], and phenotypic variation between cases has been documented [4-9]. However, genotype-phenotype correlations have not yet been fully established. The R79H mutation identified in our patient is common in the USA and European populations with the infantile form of AD [4-7], but our patient did not present with the typical clinical signs of the infantile form such as megalencephaly, developmental deterioration, and seizures from early infancy. The white matter lesions detected in our patient by MRI were not as extensive as lesions previously reported in patients with this mutation [4, 7]. In addition, we did not detect widespread damage of white matter upon analysis of somatosensory evoked potentials (normal central conduction time). Since other Oriental patients with the R79H mutation have not been reported, clinical heterogeneity could be a result of racial differences. However, racial differences have not been linked to other GFAP mutations including R79C and R239C. Disease phenotype of patients with mutations at residue 79 
N. Asahina, et al. 8

is less severe than that seen in patients with mutations at residue 239, which are also common in the infantile form [4]. Thus, patients with mutations at residue 79 who did not develop macrocephaly or marked impairment of psychomotor development have been reported [4]. As shown in Table 1, the clinical findings associated with the R79H mutations are variable. Our patient is the mildest case of AD so far reported, developing seizures relatively late at the age of five years, and presenting only with dysarthria and mild clinical symptoms. This comparison suggests that our patient could be classified as having an infantile-juvenile form of $\mathrm{AD}$, which extends the clinical spectrum associated with the R79H mutation.

In conclusion, the findings from the case presented here suggest that expression of disease caused by the R79H mutation of the GFAP gene is pleiotropic. Genotypephenotype correlations in $\mathrm{AD}$ appear to be complicated, and further comprehensive studies are required to re-establish the classification of AD based on molecular pathogenesis. 
N. Asahina, et al. 9

\section{Acknowledgements}

The authors wish to thank Dr. Keiko Tateno for referring the patient. 
N. Asahina, et al. 10

\section{References}

[1] Alexander WS. Progressive fibrinoid degeneration of fibrillary astrocytes associated with mental retardation in a hydrocephalic infant. Brain 1949;72:373-381.

[2] van der Knaap MS, Naidu S, Breiter SN, Blaser S, Stroink H, Springer S, et al.

Alexander disease: diagnosis with MR imaging. Am J Neuroradiol 2001;22:541-552.

[3] Brenner M, Johnson AB, Boespflug-Tanguy O, Rodriguez D, Goldman JE, Messing

A. Mutations in GFAP, encoding glial fibrillary acidic protein, are associated with

Alexander disease. Nat Genet 2001;27:117-120.

[4] Rodriguez D, Gauthier F, Bertini E, Bugiani M, Brenner M, N’Guyen S, et al.

Infantile Alexander disease: spectrum of GFAP mutations and genotype-phenotype correlation. Am J Hum Genet 2001;69:1134-1140.

[5] Shiroma N, Kanazawa N, Kato Z, Shimozawa N, Imamura A, Ito M, et al.

Molecular genetic study in Japanese patients with Alexander disease: a novel mutation,

R79L. Brain Dev 2003;25:116-121. 
N. Asahina, et al. 11

[6] Gorospe JR, Naidu S, Johnson AB, Puri V, Raymond GV, Jenkins SD, et al.

Molecular findings in symptomatic and pre-symptomatic Alexander disease patients.

Neurology 2002;58:1494-1500.

[7] Meins M, Brockmann K, Yadav S, Haupt M, Sperner J, Stephani U, et al. Infantile Alexander disease: a GFAP mutation in monozygotic twins and novel mutations in two other patients. Neuropediatrics 2002;33:194-198.

[8] Shiihara T, Kato M, Honma T, Ohtaki S, Sawaishi Y, Hayasaka K. Fluctuation of computed tomographic findings in white matter in Alexander's disease. J Child Neurol 2002;17:227-230.

[9] Suzuki Y, Kanazawa N, Takenaka J, Okumura A, Negoro T, Tsujino S. A case of infantile Alexander disease with a milder phenotype and a novel GFAP mutation, L90P. Brain Dev 2004;26:206-208.

[10] Springer S, Erlewein R, Naegele T, Becker I, Auer D, Grodd W, et al. Alexander disease - classification revisited and isolation of a neonatal form. Neuropediatrics 
N. Asahina, et al. 12

\section{Figure legends}

Fig. 1. Neuroimaging studies of the patient. (A) Axial T2-weighted MR image shows a periventricular rim and high-intensity signal in the bilateral frontal white matter and basal ganglia. (B) Axial T1-weighted MR image shows a poorly defined periventricular rim and a low-intensity signal in the bilateral frontal white matter and basal ganglia. (C) Contrast-enhanced MRI indicates enhancement in parts of frontal white matter adjacent to the frontal horns. (D) ${ }^{18}$ F-FDG Positron Emission Tomography shows mild hypometabolism of the bilateral frontal lobe. 


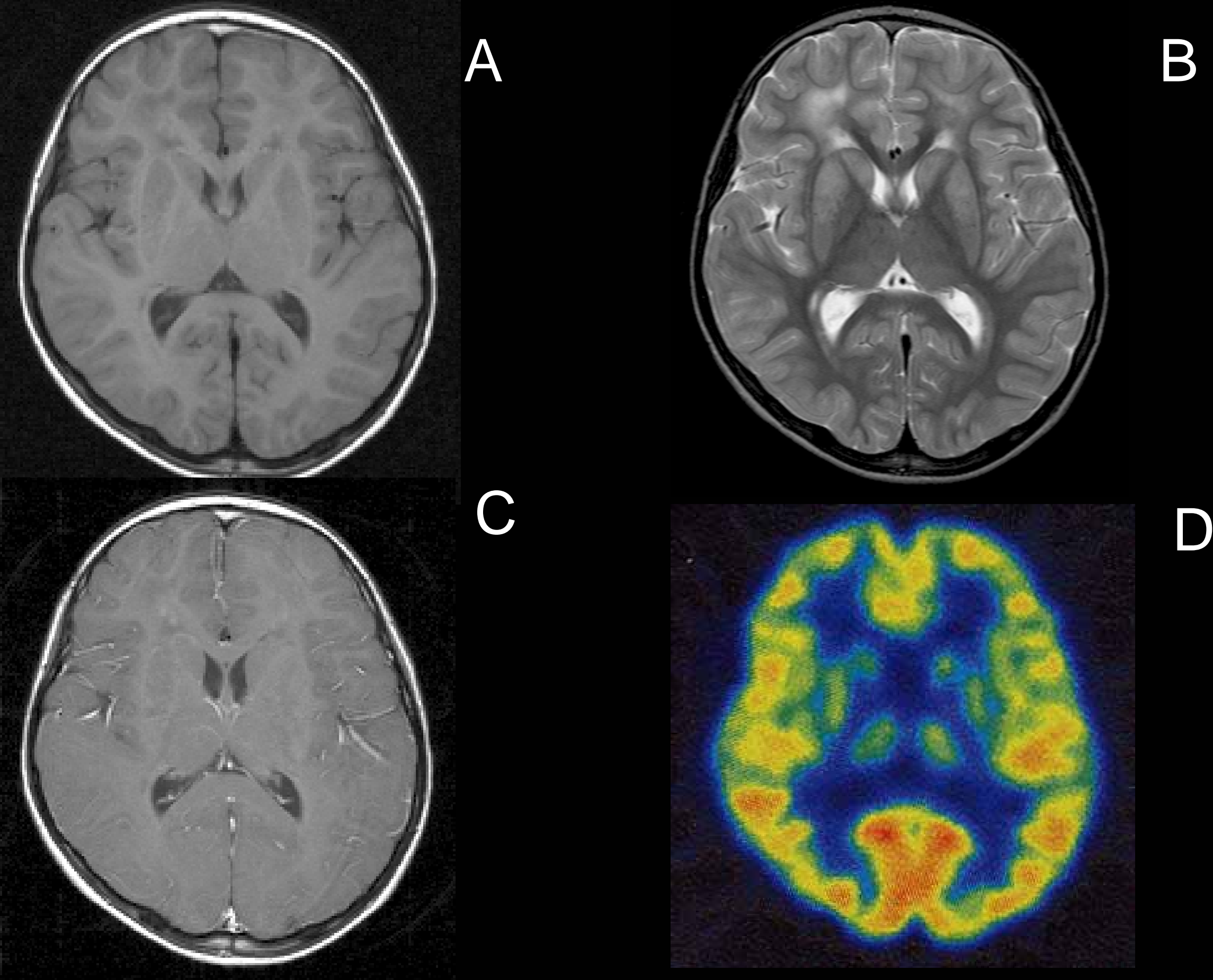


Table 1. Clinical findengs in patients with an R79H mutation.

\begin{tabular}{|c||c|c|c|c|c|c|c|c|c|}
\hline $\begin{array}{c}\text { Patient } \\
\text { number }\end{array}$ & $\begin{array}{c}\text { present } \\
\text { age(years)/sex }\end{array}$ & $\begin{array}{c}\text { initial symptom } \\
\text { /onset(months) }\end{array}$ & $\begin{array}{c}\text { onset of } \\
\text { seizures(months) }\end{array}$ & macrocephaly & ataxia & $\begin{array}{c}\text { bulbar } \\
\text { sign }\end{array}$ & spasticity & $\begin{array}{c}\text { psychomotor } \\
\text { deterioration }\end{array}$ & reference \\
\hline \hline 1 & $8.5 / \mathrm{M}$ & seizure/61 & 61 & - & - & + & - & - & our case \\
\hline 2 & $7.5 / \mathrm{NA}$ & delay/0 & $<18$ & - & - & $\mathrm{NA}$ & - & + & {$[4]$} \\
\hline 3 & 3/NA & seizure/8 & 8 & - & - & NA & - & - & {$[4]$} \\
\hline 4 & $5 / \mathrm{NA}$ & delay/6 & $<18$ & - & - & NA & - & - & {$[4]$} \\
\hline 5 & $20 / \mathrm{NA}$ & seizure/6 & 6 & - & - & NA & - & + & {$[4]$} \\
\hline 6 & 9/M & seizure/18 & 18 & + & NA & + & - & + & {$[6]$} \\
\hline 7 & 2/M & seizure/18 & 18 & + & NA & - & + & - & {$[6]$} \\
\hline 8 & $10 / \mathrm{M}$ & delay/6 & $12 \sim 24$ & + & + & NA & + & + & {$[7]$} \\
\hline 9 & $10 / \mathrm{M}$ & delay/6 & $12 \sim 24$ & + & + & NA & + & + & {$[7]$} \\
\hline
\end{tabular}

mean ,but their length and weight were 2 SD bélow the mean. Thus they were classified in macrocephaly $(+)$ group. NA=not apricable. 